\title{
A new argument from interpersonal variation to subjectivism about color: a response to Gómez-Torrente
}

Article

Accepted Version

Hansen, N. (2017) A new argument from interpersonal variation to subjectivism about color: a response to GómezTorrente. Noûs, 51 (2). pp. 421-428. ISSN 1468-0068 doi: https://doi.org/10.1111/nous.12103 Available at https://centaur.reading.ac.uk/45789/

It is advisable to refer to the publisher's version if you intend to cite from the work. See Guidance on citing.

To link to this article DOI: http://dx.doi.org/10.1111/nous.12103

Publisher: Wiley

All outputs in CentAUR are protected by Intellectual Property Rights law, including copyright law. Copyright and IPR is retained by the creators or other copyright holders. Terms and conditions for use of this material are defined in the End User Agreement.

www.reading.ac.uk/centaur 
Central Archive at the University of Reading

Reading's research outputs online 


\title{
A New Argument from Interpersonal Variation to Subjectivism about Color: A Response to Gómez-Torrente
}

\author{
Nat Hansen \\ Forthcoming in Nô̂s
}

\begin{abstract}
I describe a new, comparative, version of the argument from interpersonal variation to subjectivism about color. The comparative version undermines a recent objectivist response to standard versions of that argument (Gómez-Torrente 2014).
\end{abstract}

\section{The argument from interpersonal variation in color judgments to subjectivism about color}

A central argument in support of the idea that colors are subjective- that they essentially involve relations to perceiving subjects-is the argument from interpersonal variation in how normal observers perceive color. One way of formulating the argument goes as follows:

1. There is widespread apparent disagreement among normal observers over what count as "unique" hues in the blue-green range. ${ }^{1}$

2. There is no good reason to think that one normal observer's judgment that $x$ is unique green (not at all bluish or yellowish) is veridical while another normal observer's judgment that $x$ is not unique green (because it is bluish) is not. Either both judgments are veridical, or neither is. ${ }^{2}$

3. The idea that neither judgment is veridical (perhaps because colors don't exist) is implausible. ${ }^{3}$

4. So we have reason to think that both judgments ( $x$ is unique green and $x$ is not unique green) are veridical.

5. But if both judgments are veridical, then they must not contradict one another.

6. The best way to avoid contradiction is to think of the contents expressed by $x$ is unique green and $x$ is not unique green as subject-relative: as $x$ is unique green to Wy and $x$ is not unique green to Zed. Those contents can both be true of the same object at the same time. ${ }^{4}$ 


\section{A new objectivist response to the argument from interpersonal variation}

Gómez-Torrente (2014) offers a novel way for a defender of objectivism about color (which he characterizes as the view that color properties do not essentially involve relations to perceiving subjects) to respond to the argument from interpersonal variation while accepting all of the argument's premises (1-5). He does so by drawing an analogy between color adjectives ("green", "blue", etc.) and gradable adjectives that measure objective magnitudes. ${ }^{5}$

A standard semantics for gradable (or scalar) adjectives like "tall" and "hot" associates such adjectives with scales. A scale is a set of degrees ordered along some dimension (height, temperature, etc.). Adjectives like "tall" and "hot" locate objects on a scale relative to a context-sensitive standard: 35 degree water may count as "hot" for Zed, but may not count as hot for Wy, for example. ${ }^{6}$ In such a situation, when Wy and Zed describe something as "hot", their intentions fix different standards that something must meet or exceed on the scale of hotness in order to count as hot. (See figures 1 and 2, which are based on Gómez-Torrente (2014, figure 1).)

Figure 1: Wy's standards on the dimension of temperature

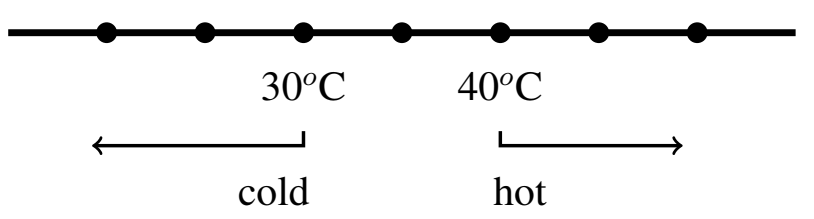

Figure 2: Zed's standards on the dimension of temperature

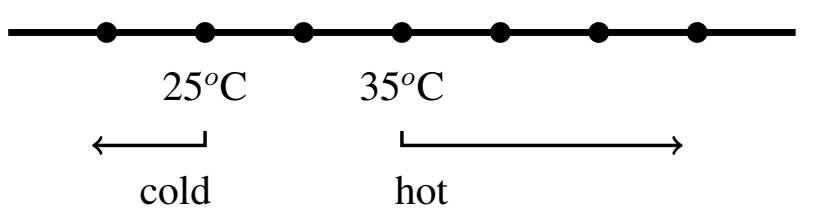

Figures 1 and 2 show that by setting the standards for what counts as "hot" in different places, Wy and Zed can disagree over whether something is hot (e.g., water that is $35^{\circ} \mathrm{C}$ ): Wy will judge that it isn't hot, and Zed will judge that it is. The adjectives "tall" and "hot", though they have standards that may differ between subjects, still order objects along scales that measure objective dimensions: namely height and temperature, respectively. When standards are set in different places on the scale of hotness, it is possible for two people to make apparently contradictory judgments ( $x$ is hot and $x$ is not hot), that are nevertheless both veridical. When Zed says " $\mathrm{x}$ is hot" (in a context where his standard for what counts as hot is being at least $35^{\circ} \mathrm{C}$ ), he says something true just in case $\mathrm{x}$ has a temperature of at least $35^{\circ} \mathrm{C}$. When Wy says " $\mathrm{x}$ is not hot" (in a context where his standard for what counts as hot is being at least $40^{\circ} \mathrm{C}$ ), what he says is true just in case $\mathrm{x}$ doesn't have a temperature of at least $40^{\circ} \mathrm{C}$. So when $\mathrm{x}$ is $35^{\circ} \mathrm{C}$, Wy can truly say " $\mathrm{x}$ is not hot" and Zed can truly say that " $\mathrm{x}$ is hot". ${ }^{7}$ So even though the way content is "fixed" involves subjective aspects of 
speakers (their intentions, e.g.), the content that is thereby fixed can be objective ("x is hot" is true just in case $\mathrm{x}$ has a temperature of at least $40^{\circ} \mathrm{C}$, e.g.) (Gómez-Torrente, 2014, p. 7).

Gómez-Torrente's central claim is that color adjectives operate the same way as "hot" and "tall": the appearance of interpersonal disagreements over whether something is unique green or not stem from locating the relevant standard in different places on a scale of hue that is a way of ordering degrees on an underlying objective dimension. Gómez-Torrente wants to remain neutral between competing objectivist accounts of what the colors are, so he lets the variable $h$ stand for a degree on whatever objective dimension (dominant wavelength, e.g.) is supposed to correspond to the hue dimension. Different degrees on the objective dimension can then be ordered into a scale of hues, as in figures 3 and 4 (which are based on Gómez-Torrente (2014, figure 2)).

If color adjectives like "green" have varying standards in the same way that "tall" and "hot" do, then disagreements over whether some hue is unique green or not can be explained as disagreements over where the standards of greenness are located on the scale of hues. So, for example, Wy may judge that $x$ is unique green, while Zed judges that $x$ is not unique green (because it's too blue). In so judging, Wy would be saying something true just in case $\mathrm{x}$ is located between $h_{0}$ (his standard for what makes something count as minimally blue) and $h_{1}$ (his standard for what makes something count as minimally yellow) (see figure 3). Zed's judgment that $h$ is not unique green would be true just in case $\mathrm{x}$ is not located between $h$ (his standard for what makes something count as minimally blue) and $h_{2}$ (his standard for what makes something count as minimally yellow). (See figure 4.)

If that approach is right, then the phenomenon of intersubjective variation in judgments about unique hues is compatible with an objectivist view of color-it can be understood as the result of locating the relevant standards for, e.g., "blue", "green", and "yellow" in different places on the scale of hues.

Figure 3: Wy's standards on the dimension of hues

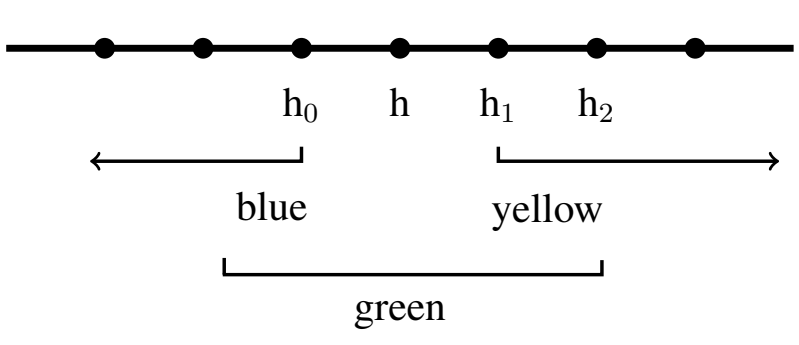

\section{A Comparative Version of the Argument from Interpersonal Variation}

Gómez-Torrente provides a way for the objectivist about color to respond to the standard argument from interpersonal variation in judgments about the unique hues to subjectivism about color while hanging on to the plausible premises of the argument. But there is a variant of the argument from interpersonal variation that shows that the objectivist can't embrace both the idea that color adjectives refer to an objective dimension of hue and that 
Figure 4: Zed's standards on the dimension of hues

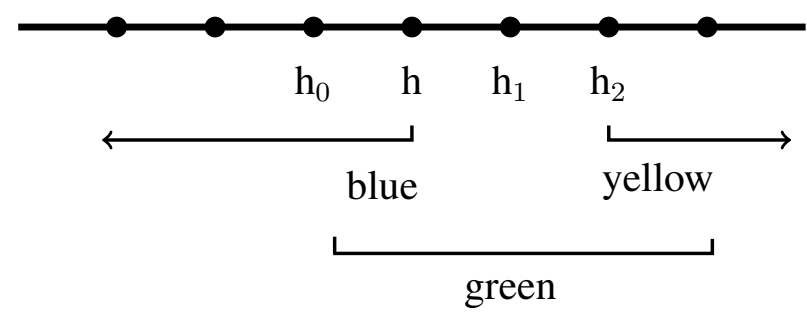

the conflicting judgments of normal observers are simultaneously veridical. The variant of the argument involves comparative judgments of hue ( $x$ is greener than $y$ ), rather than categorical judgments ( $x$ is unique green).

If Wy thinks that $\mathrm{h}$ is unique green, and Zed doesn't, then they will also disagree about whether $\mathrm{h}$ is greener than certain other objects or not. For example, Wy will find h greener than $\mathrm{h}_{1}$, and Zed will find $\mathrm{h}_{1}$ greener than $\mathrm{h}$ (see figures 3 and 4 ). This is not just a difference in where $\mathrm{Wy}$ and Zed locate their standards for greenness on the objective dimension that is supposed to correspond to hue, it is a difference in how Wy and Zed order hues on scales of greenness.

Contrast the fact that the scales Wy and Zed associate with "green" can be differently ordered with the clearly objective scales that are associated with "tall" and "hot": If Wy and Zed disagree about which of two objects is taller or hotter, then one of them has to be making a mistake. That's because the scales associated with "tall" and "hot" align with objective dimensions of height and temperature. Imagine how odd "tall" and "hot" would look if it were possible for two people to (veridically) disagree about the ordering of degrees on the dimensions of height and temperature:

- Wy: $40^{\circ} \mathrm{C}$ is hotter than $35^{\circ} \mathrm{C}$.

- Zed: $40^{\circ} \mathrm{C}$ is not hotter than $35^{\circ} \mathrm{C}$.

Only if Zed is using "hotter" (or one of the other words in the sentence) to mean something idiosyncratic could what he says be veridical.

That's not the case with color adjectives. Wy and Zed can disagree about the proper ordering of objects in terms of how green they are while both still making veridical judgments. That means that they are operating with different scales of greenness. The ordering of a scale associated with a gradable adjective is an essential part of its meaning, as polar antonyms like "hot" and "cold" make clear. "Hot" and "cold" share the same underlying dimension (temperature), but order the degrees on that scale in different directions.

The objectivist could argue that the different ways that "cold" and "hot" order the underlying objective dimension of temperature is in fact a good way of understanding the way that different perceiving subjects can order the underlying objective dimension of hue. ${ }^{8}$ On the standard semantics for gradable adjectives that Gómez-Torrente invokes, a comparative construction (" $\mathrm{x}$ is hotter than $\mathrm{y}$ ", "x is greener than $\mathrm{y}$ ") is true just in case $\mathrm{x}$ has a greater 
degree on the relevant scale (hotness, greenness) than y. "Hot" and "cold" order the underlying dimension of temperature in opposite directions, so that even if $\mathrm{x}$ and $\mathrm{y}$ have constant temperatures, then both the judgment $x$ is hotter than $y$ and the judgment $y$ is colder than $x$ can simultaneously be true: " $y$ is colder than $x$ " is true just in case $y$ is closer to absolute zero than $\mathrm{x}$; " $\mathrm{x}$ is hotter than $\mathrm{y}$ " is true just in case $\mathrm{x}$ is further away from absolute zero than $\mathrm{y}$ is. Maybe Wy and Zed's different scales for greenness function in a similar way.

Wy's judgment that $h$ is greener than $h_{1}$ is true just in case $\mathrm{h}$ is closer to what he considers to be unique green (h) than $\mathrm{h}_{1}$ is. Assuming that identity is maximal closeness, then because $\mathrm{h}$ is what $\mathrm{Wy}$ judges to be unique green, his judgment $h$ is greener than $h_{1}$ is true. Zed's judgment that $h_{1}$ is greener than $h$ is true just in case $h_{1}$ is closer to what he considers to be unique green $\left(h_{1}\right)$ than $h$ is. Since $h_{1}$ is what Zed judges to be unique green, then his judgment is true. And it might appear that the truth conditional content of both judgments can be spelled out purely objectively, in terms of the objective properties $\mathrm{h}$ and $\mathrm{h}_{1}$, with subjective features of $\mathrm{Wy}$ and Zed only playing a role in fixing the relevant contents.

But a key aspect of the truth conditional content of the comparative color judgments, the notion of closeness or proximity to unique green, can't plausibly be defined without invoking a subject-relative property, even once interpersonal differences in what counts as unique green are fixed to objective properties ( $h$ or $h_{1}$, e.g.). That's because there can be interpersonal variation in judgments about which hues (on the objective dimension of hue) are closer to unique green.

For example, assume that Wy and Zed are participating in an experiment where they are presented with spectral light stimuli, and that both judge that light at $516 \mathrm{~nm}$ is unique green. ${ }^{9}$ But even if they locate unique green in the same place on the objective dimension of wavelength, they can disagree about whether, e.g., light at $510 \mathrm{~nm}$ (shifted slightly towards blue) or at $522 \mathrm{~nm}$ (shifted slightly towards yellow) is greener (closer to unique green). If both Wy and Zed's judgment are veridical, then that means that closeness to unique green can't be defined in terms of distance along the dimension of wavelength (mutatis mutandis for other candidates for the objective dimension that is supposed to correspond with hues: dominant wavelength, surface spectral reflectance, etc.). A partial explanation for the fact that this type of comparative variation is possible is the existence of lower-level physiological differences between subjects (screening pigments or numbers of cone types, e.g. (Malkoc et al., 2005, p. 2155)), or higher-level differences between subjects (past visual experiences, e.g. (Hinks et al., 2007, p. 3371)).

So, assuming the veridicality of both Wy and Zed's comparative judgments of hue, the truth conditions for comparative judgments of hue ( $x$ is greener than $y$ ) involve an element that can't plausibly be spelled out in non-subject-involving terms, namely closeness to unique green. That blocks Gómez-Torrente's attempt to show that subjective features only play a content-fixing role and don't contribute to the truth conditional content of judgments involving color adjectives.

The argument from interpersonal variation can therefore be reformulated in comparative terms, as follows: 
1. There is widespread apparent disagreement among normal observers over what count as examples of unique hues in the blue-green range.

2. If there is widespread apparent disagreement among normal observers about the location of unique hues in the blue-green range, then there is widespread apparent disagreement among normal observers over comparative judgments of hue in the blue-green range.

3. There is therefore widespread apparent disagreement among normal observers over comparative judgments of hue in the blue-green range.

4. There is no good reason to think that one normal observer's judgment that $x$ is greener than $y$ is veridical while another normal observer's judgment that $y$ is not greener than $x$ is not. Either both judgments are veridical, or neither is.

5. The idea that neither judgment is veridical (perhaps because colors don't exist) is implausible.

6. So we have reason to think that both judgments ( $x$ is greener than $y$ and $x$ is not greener than y) are veridical.

7. But if both judgments are veridical, then they must not contradict one another.

8. The best way to avoid contradiction is to think of the contents expressed by $x$ is greener than $y$ and $x$ is not greener than $y$ as subject-relative: as $x$ is greener than $y$ to Wy and $x$ is not greener than y to Zed. Those contents can both be true of the same object at the same time.

It is, of course, open to the defender of the objectivity of hue to respond to the comparative argument from interpersonal variation by rejecting premise (4), and arguing that there is a reason to think that certain comparative judgments are veridical while others are not. Such a response is a version of the standard objectivist response to the argument from interpersonal variation. So, for example, one might argue that someone who judges that $516 \mathrm{~nm}$ light is unique green but who judges that $522 \mathrm{~nm}$ (slightly more yellowish) light is greener than 510nm (slightly more bluish) light is simply making a mistakeobjectively, both $510 \mathrm{~nm}$ and $522 \mathrm{~nm}$ light are equally close to unique green, and therefore equally green. ${ }^{10}$ But responding to the argument in that way eliminates the central appeal of Gómez-Torrente's objectivist response to the argument from interpersonal variationnamely, that it does not require simply overriding the judgments of normal observers with an objective standard of correctness for judgments about color.

\section{Multidimensionality?}

Someone might respond to the previous line of argument by pointing out that there are adjectives, like "big", that order objects along obviously objective dimensions, and for which there can be apparent disagreements about comparative judgments (of bigness), and for which the comparative judgments can both be veridical. Wy and Zed might, for example, disagree over who is bigger: Kareem Abdul-Jabbar $(2.18 \mathrm{~m}, 102 \mathrm{~kg}$ ), or Hulk Hogan $(2.01 \mathrm{~m}, 137 \mathrm{~kg})$. If Wy's scale for "big" gives more weight to height than mass, then he can veridically judge that Abdul-Jabbar is bigger than Hulk Hogan. If Zed's scale for "big" gives more weight to mass than to height, then he can veridically judge the reverse. 
The existence of veridical comparative judgments about a property that seem to contradict each other therefore doesn't mean that the property can't be objective. The apparent disagreement can be explained in terms of different weightings assigned to the dimensions that produce the scale on which objects are ordered. Perhaps comparative judgments about color are like "big" in that respect.

Judgments about color are undoubtedly multidimensional, and some forms of apparent disagreement over colors can be explained in terms of differences in relative weighting of dimensions. So, for example, Wy and Zed may disagree over whether a yellowish green (less green than a focal green in terms of hue) is more or less green than a pale mint green (less green than a focal green in terms of saturation) because they assign different weightings to the dimensions of hue and saturation in how they order objects in terms of (overall) greenness.

But the variation in the new comparative argument from interpersonal variation relies only on variation in judgments about hue, which for Gómez-Torrente is mapped onto a single objective dimension. So it's not available to Gómez-Torrente to explain the existence of apparently veridical, but conflicting comparative judgments in terms of different weightings of dimensions.

\section{Conclusion}

In this brief essay I haven't given direct support for the argument from interpersonal variation to subjectivism about color. My aim has been to show that Gómez-Torrente's recent, appealing attempt to accept the premises of that argument while embracing objectivism about color succeeds only if it is directed against a non-comparative version of the argument. Once the argument is couched in terms of interpersonal variation in comparative judgments of hue, it is impossible to embrace the idea that the comparative judgments are veridical without giving up on the idea that colors are objective properties. ${ }^{11}$

\section{Notes}

${ }^{1}$ Unique hues are "phenomenally simple", meaning that they do not appear to be mixtures of other hues. A unique green, for example, does not appear to contain any blue or any yellow (see Hardin 1988 for discussion). Gómez-Torrente (2014, §1), Cohen (2004, $\S 3.2$ ), and Cohen $(2009, \S 2.3 .2)$ (and citations therein) discuss the evidence in support of the claim that there is widespread variation in where the unique hues are located. Allen (2010) questions whether the empirical evidence actually supports the claim that there is such widespread variation.

${ }^{2}$ Objectivists such as Byrne and Hilbert (2003), Byrne (2006) and Tye (2006) would reject this premise.

${ }^{3}$ Eliminativists (Hardin 1988, e.g.) would reject this premise.

${ }^{4}$ The conclusion can be spelled out either in terms of indexical contextualism (Cohen, 2004) or "perspectivalism", a form of non-indexical contextualism (Brogaard, 2010, 2012) 
according to which the truth of the invariant content $x$ is unique green is relativized to different perceiving subjects. See Cohen (2015) for discussion of the two views.

${ }^{5}$ Though his argument turns on features of color language, Gómez-Torrente argues that his conclusions about language extend to color experience on the "natural" supposition that "the color properties signified by color words are represented by color experience" (p. 2).

${ }^{6}$ Gómez-Torrente draws on the degree-based semantics for gradable adjectives given in Kennedy (2007).

${ }^{7}$ The apparent disagreement between Wy and Zed in such a situation might be explained in terms of a disagreement over what the relevant standard for being hot is or should be, not what the temperature of the object is. See Plunkett and Sundell (2013) for a discussion of this kind of "metalinguistic" disagreement.

8"Mild" is a temperature adjective that corresponds more closely with the structure of color terms than "hot" and "cold", because it involves a focal point that temperatures can diverge from in two directions on the dimension of temperature: $\mathrm{x}$ can be milder than $\mathrm{y}$ because it is colder than y (if y is hot), or because it is hotter than y (if y is cold). Thanks to Mark Pinder and Jérémy Zehr for discussion.

${ }^{9}$ See Volbrecht et al. (1997) for an example of an experiment evaluating the location of unique hues involving spectral light against different backgrounds.

${ }^{10}$ Thanks to Mario Gómez-Torrente and Mark Pinder for discussion of this possibility.

${ }^{11}$ Thanks to Zed Adams, Jonas Åkerman, Jonathan Cohen, Mario Gómez-Torrente, Jumbly Grindrod, Wyeth Hansen, Melody Drummond Hansen, Eliot Michaelson, Chauncey Maher, Mark Pinder, Jérémy Zehr, and an anonymous referee for very helpful comments.

\section{References}

Allen, K. (2010). Locating the unique hues. Rivista di Estetica, 43(1):13-28.

Brogaard, B. (2010). Perspectival truth and color primitivism. In Wright, C. and Pedersen, N., editors, New Waves in Truth. Palgrave MacMillan, New York, NY.

Brogaard, B. (2012). Colour eliminativism or colour relativism? Philosophical Papers, 41(2):305-321.

Byrne, A. (2006). Comments on Cohen, Mizrahi, Maund, and Levine. dialectica, 60(3):337-340.

Byrne, A. and Hilbert, D. (2003). Color realism and color science. Behavioral and Brain Sciences, 26:3-21.

Cohen, J. (2004). Color properties and color ascriptions: A relationalist manifesto. The Philosophical Review, 113(4):451-506.

Cohen, J. (2009). The Red and the Real: An Essay on Color Ontology. Oxford University Press, Oxford. 
Cohen, J. (2015). Ecumenicism, comparability, and color, or: How to have your cake and eat it too. forthcoming in Minds and Machines.

Gómez-Torrente, M. (2014). Perceptual variation, color language, and reference fixing. an objectivist account. Noûs, early view:1-38.

Hardin, C. (1988). Color for Philosophers: Unweaving the Rainbow. Hackett, Indianapolis, expanded edition.

Hinks, D., Cárdenas, L. M., Kuehni, R. G., and Shamey, R. (2007). Unique-hue stimulus selection using munsell color chips. Journal of the Optical Society of America A, 24(10):3371-3378.

Kennedy, C. (2007). Vagueness and grammar: the semantics of relative and absolute gradable adjectives. Linguistics and Philosophy, 30(1):1-45.

Malkoc, G., Kay, P., and Webster, M. A. (2005). Variations in normal color vision. iv. binary hues and hue scaling. Journal of the Optical Society of America A, 22(10):2154-2168.

Plunkett, D. and Sundell, T. (2013). Disagreement and the semantics of normative and evaluative terms. Philosophers' Imprint, 13(23):1-37.

Tye, M. (2006). The truth about true blue. Analysis, 66(4):340-344.

Volbrecht, V. J., Nerger, J. L., and Harlow, C. E. (1997). The bimodality of unique green revisited. Vision Research, 37(4):407-416. 